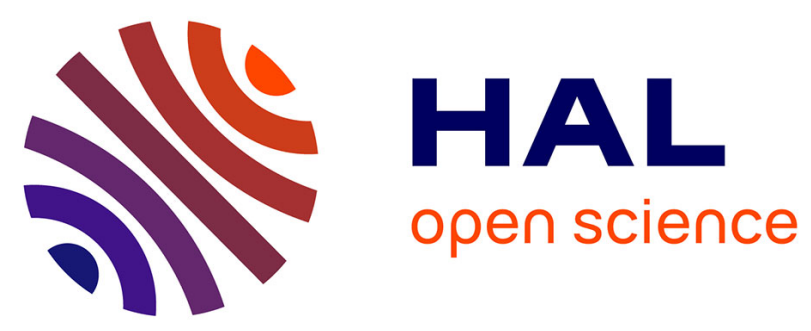

\title{
Vibration of a Square Hyperelastic Plate Around Statically Pre-Loaded State
}

\author{
Ivan Breslavsky, Mathias Legrand, Marco Amabili
}

\section{To cite this version:}

Ivan Breslavsky, Mathias Legrand, Marco Amabili. Vibration of a Square Hyperelastic Plate Around Statically Pre-Loaded State. ASME IDETC/CIE Conference, Aug 2014, Buffalo, United States. 10.1115/DETC2014-35382 . hal-01195752

\section{HAL Id: hal-01195752 \\ https://hal.science/hal-01195752}

Submitted on 8 Sep 2015

HAL is a multi-disciplinary open access archive for the deposit and dissemination of scientific research documents, whether they are published or not. The documents may come from teaching and research institutions in France or abroad, or from public or private research centers.
L'archive ouverte pluridisciplinaire HAL, est destinée au dépôt et à la diffusion de documents scientifiques de niveau recherche, publiés ou non, émanant des établissements d'enseignement et de recherche français ou étrangers, des laboratoires publics ou privés. 


\section{VIBRATION OF A SQUARE HYPERELASTIC PLATE AROUND STATICALLY PRE- LOADED STATE}

\author{
Ivan D. Breslavskyi \\ Department of Mechanical \\ Engineering \\ McGill University \\ Montréal, Québec, H3A 0C3 \\ Canada \\ Ivan.breslavskyi@mcgill.ca
}

\author{
Mathias Legrand \\ Department of Mechanical \\ Engineering \\ McGill University \\ Montréal, Québec, H3A 0C3 \\ Canada \\ mathias.legrand@mcgill.ca
}

\author{
Marco Amabili \\ Department of Mechanical \\ Engineering \\ McGill University \\ Montréal, Québec, H3A 0C3 \\ Canada \\ marco.amabili@mcgill.ca
}

\begin{abstract}
Static deflection and free nonlinear vibrations of thin square plate made of biological material are investigated. The involved physical nonlinearity is described through NeoHookean, Mooney-Rivlin and Ogden hyperelastic laws; geometrical nonlinearity is modeled by Novozhilov nonlinear shell theory. The problem is solved by sequentially constructing the local models that describe the behavior of plate in the vicinity of a certain static configuration. These models are the systems of ordinary differential equations with quadratic and cubic nonlinear terms in displacement, which allows application of techniques used in analysis of thin-walled structures of physically linear materials. The comparison of static and dynamic results obtained with different material models is carried out.
\end{abstract}

\section{INTRODUCTION}

Dynamic properties of structures made of materials that are not linearly elastic are poorly understood. They are currently being investigated in many research areas and increasingly used in engineering, more specifically in biomedical engineering, because they can model the mechanical properties of real soft tissues.

Most of studies on shell-type structures of hyperelastic materials involve using finite elements approach $[1,2]$, which requires large number of degrees of freedom. This significantly complicates the investigation of the dynamics. Another widely used simplification is the assumption of known simple shape of the structure after deformation (see, for example, [3, 4]). However, this assumption also is valid mostly in static problems.
Another approach, that does not have the drawbacks of the above-mentioned ones, is used in this study. The approach consists in the meshless approximation of the deformed shape by truncated series of eigenmodes with the convergence study of the series. Such approach is frequently employed in problems of shells made of linear materials and also was applied to solve problems of hyperelastic plates [5, 6] and membranes [7-9]. Also it was used in the problem with another type of physical nonlinearity [10].

The present study uses a general methodology dedicated to exploration of the statics as well as the dynamics of a square plate made of biomaterial. The material nonlinearity is captured by Neo-Hookean, Mooney-Rivlin and Ogden hyperelastic laws in order to reproduce a key structural feature of biological materials that is a sharp increase in stiffness above a strain threshold. The geometrical nonlinearity induced by large displacements is also accounted for through Novozhilov's plate theory. The results obtained with different material models are compared.

\section{GEOMETRICAL AND PHYSICAL PARAMETERS OF THE PROBLEM}

A square plate made of biomaterial is considered. It is defined on the following domain:

$$
V=\left\{x \in[0, a] ; y \in[0, b] ; z \in\left[\frac{-h}{2}, \frac{h}{2}\right]\right\}
$$

with $a=0.1 \mathrm{~m}, b=0.1 \mathrm{~m}, h=0.0005 \mathrm{~m}$.

We aimed to model only the key feature of soft biological tissues, i.e., a sharp increase in stiffness after a given strain threshold is reached. The experimental data for the adventitia of human aorta from [11] were approximated by Neo-Hookean, 
Mooney-Rivlin and Ogden hyperelastic laws. Also, linear material model is used. The strain energy densities for these laws are given in Tab. 1.

Table 1. STRAIN ENERGY DENCITIES FOR DIFFERENT MATERIAL MODELS.

\section{Neo-Hookean $[12,13] \quad W=\frac{E}{6}\left(I_{1}-3\right)$}

(1)

Mooney-Rivlin $\quad\left[12, \quad W=\frac{\mu_{1}}{2}\left(I_{1}-3\right)+\frac{\mu_{2}}{2}\left(I_{2}-3\right)\right.$
$13] \quad(2)$

13]

(2)

$\overline{\text { Ogden [12] } \quad W=\sum_{i=1}^{N_{T}} \frac{\mu_{i}}{\alpha_{i}}\left(\lambda_{1}^{\alpha_{i}}+\lambda_{2}^{\alpha_{i}}+\lambda_{3}^{\alpha_{i}}-3\right)(3)}$

Plate of linear material $[5,14]$

$$
W=\frac{E}{6}\left(4\left(\varepsilon_{1}^{2}+\varepsilon_{2}^{2}+\varepsilon_{1} \varepsilon_{2}\right)+\right.
$$$$
\left.\varepsilon_{12}^{2}\right)(4)
$$

In Tab. $1, I_{1}$ is the first invariant of the right Cauchy-Green deformation tensor $\mathbf{C}$; $E$ is the Young's modulus of the plate's material; $I_{2}$ stands for the second invariant of the right CauchyGreen deformation tensor; $\lambda_{1}, \lambda_{2}, \lambda_{3}$ are the principal stretches of the plate; $\varepsilon_{i}$, are the components of the Green-Lagrange strain tensor for thin plates.

The parameters of the models (1-4) $E, \mu_{i}, \alpha_{i}$ are fitted to experimental data by least-squares method. The stress-strain diagram and experimental points for uniaxial tension for material under consideration are shown in Fig. 1.

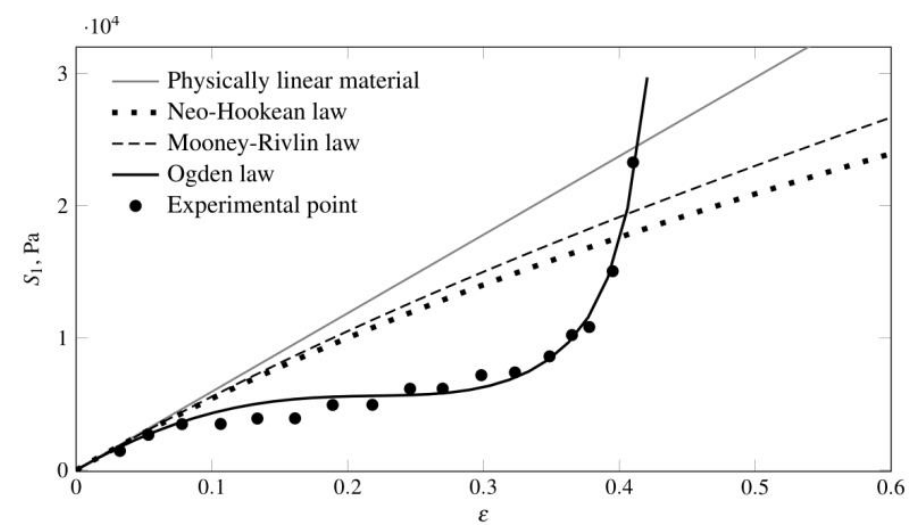

Figure 1. STRESS-STRAIN CURVES AND EXPERIMENTAL POINTS FOR UNIAXIAL TENSION OF BIOMATERIAL.
Table 2. BIOMATERIAL PARAMETERS OF HYPERELASTIC LAWS.

\begin{tabular}{lc}
\hline Neo-Hookean & $E=59383.2 \mathrm{~Pa}$ \\
\hline Mooney-Rivlin & $\mu_{1}=25829.8 \mathrm{~Pa}, \mu_{2}=-6035.4 \mathrm{~Pa}$ \\
\hline & $\mu_{1}=466515161.8 \mathrm{~Pa}$, \\
$\mu_{2}=2.49 * 10^{-9} \mathrm{~Pa}$, \\
Ogden & $\mu_{3}=-1115907998.2 \mathrm{~Pa}$, \\
& $\mu_{4}=649412722.6 \mathrm{~Pa}$, \\
& $\alpha_{1}=7.385, \alpha_{2}=84.402$, \\
& $\alpha_{3}=7.365, \alpha_{4}=7.35$ \\
\hline
\end{tabular}

\section{CONSTITUTIVE RELATIONS}

The Lagrange equations are used to describe the dynamic behavior of the plate. The potential and kinetic energies are given by the formulas [14]:

$$
\begin{gathered}
\Pi=\iiint_{V} W d V, \\
T=\frac{\rho h}{2} \iint_{S}\left(\dot{u}^{2}+\dot{v}^{2}+\dot{w}^{2}\right) d S,
\end{gathered}
$$

where $V$ is the volume of the plate, $S$ is the surface of the middle plane of the plate, $\rho$ is the mass-density of the plate material, $h$ is the thickness of the plate and $u, v, w$ are the displacements along the axes of the rectangular coordinate system $x, y, z$, respectively. The dot stands for differentiation with respect to time.

The geometrical nonlinearity is described by Novozhilov strain-displacement relationships [14]:

$$
\begin{gathered}
\varepsilon_{1}=u_{x}+\frac{1}{2}\left(w_{x}^{2}+u_{x}^{2}+v_{x}^{2}\right)-z w_{x x} \\
\varepsilon_{2}=v_{y}+\frac{1}{2}\left(w_{y}^{2}+u_{y}^{2}+v_{y}^{2}\right)-z w_{y y} \\
\varepsilon_{12}=u_{y}+v_{x}+w_{x} w_{y}+u_{x} u_{y}+v_{x} v_{y}-2 z w_{x y} .
\end{gathered}
$$

The right Cauchy-Green deformation tensor $\mathbf{C}$ is defined as $[5,6,13]$ :

$$
\boldsymbol{C}=\left(\begin{array}{ccc}
2 \varepsilon_{1}+1 & \varepsilon_{12} & 0 \\
\varepsilon_{12} & 2 \varepsilon_{2}+1 & 0 \\
0 & 0 & 2 \varepsilon_{3}+1
\end{array}\right)
$$

The principal stretches are the square roots of the eigenvalues of $\mathbf{C}$ and three invariants can be calculated according to known formulae: 


$$
I_{1}=\operatorname{Tr}(\boldsymbol{C}), I_{2}=\frac{1}{2}\left(\operatorname{Tr}(\boldsymbol{C})^{2}-\operatorname{Tr}\left(C^{2}\right)\right), J^{2}=|\boldsymbol{C}| .
$$

However, the expression in terms of displacements for one strain component in Eqn. (8), namely for $\varepsilon_{3}$, is unknown. To obtain this expression the fact that soft biological tissues are incompressible $[12,13]$ is used. The incompressibility condition $J=1$ yields

$$
\varepsilon_{3}=\frac{1}{2\left(\left(2 \varepsilon_{1}+1\right)\left(2 \varepsilon_{2}+1\right)-\varepsilon_{12}^{2}\right)}-\frac{1}{2} .
$$

A so-called local models method is purposely developed for the problem of interest. It can be described as Newton-Raphson method with expanding at each step the non-polynomial strain energy densities Eqns. (1-3) into a truncated power series expressed in the strain components. In more details the method is described in [5].

\section{BOUNDARY CONDITIONS AND DISCRETIZATION}

The plate is simply supported with immovable edges, giving the following boundary conditions [14]:

$$
\left.w\right|_{\partial \Lambda}=\left.M\right|_{\partial \Lambda}=\left.u\right|_{\partial \Lambda}=\left.v\right|_{\partial \Lambda}=0,
$$

where $\partial \Lambda$ denotes the boundary of the plate middle surface. The bending moment per unit length $M[14]$ reads:

$$
M=-D\left(\frac{\partial^{2} w}{\partial \boldsymbol{n}^{2}}+v \frac{\partial^{2} w}{\partial \tau^{2}}\right)
$$

where $\boldsymbol{n}$ and $\boldsymbol{\tau}$ are the outer normal and tangent directions to $\partial \Lambda$, respectively.

Since the boundary conditions are linear the linear combination of the eigenmodes also satisfies them, so there is no need in additional transformations [14, 15].

In problem under considerations as well as in certain close problems the eigenmodes of linear vibrations can be expressed in terms of trigonometric functions $[14,16]$. The displacements are expanded into truncated series of eigenmodes $[5,14,17]$ :

$$
\begin{aligned}
& w(x, y, t)= \\
& \sum_{n, m \in N} w_{2 n+1,2 m+1}(t) \sin \frac{(2 n+1) \pi x}{a} \sin \frac{(2 m+1) \pi y}{b} \\
& u(x, y, t)=\sum_{n, m \in N} u_{2 n, 2 m+1}(t) \sin \frac{2 n \pi x}{a} \sin \frac{(2 m+1) \pi y}{b}
\end{aligned}
$$

$$
v(x, y, t)=\sum_{n, m \in N} v_{2 n+1,2 m}(t) \sin \frac{(2 n+1) \pi x}{a} \sin \frac{2 m \pi y}{b} .
$$

The convergence study showed that model with four summands in each of the expressions (9) provides good approximation of the solution.

\section{STATIC BENDING OF A PLATE}

Attention is now paid to the static bending of the plate under uniformly distributed pressure. The pressure-deflection curves obtained with the exact method are depicted in Fig. 2.

We can see that the Neo-Hookean and Mooney-Rivlin results are fairly similar, while the Ogden curve presents large differences at deflections higher than $80 h$ (see Fig. 2). Ogden material becomes much stiffer at these deflections.

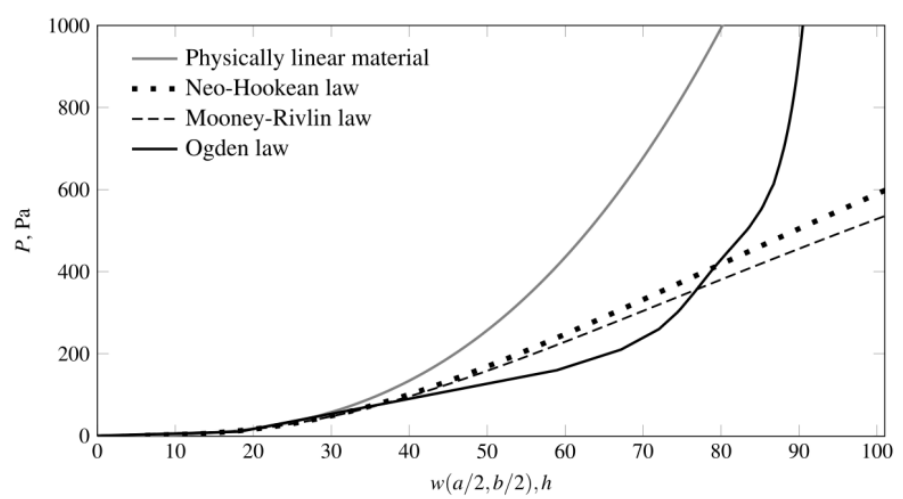

Figure 2. PRESSURE LOAD VERSUS CENTRAL DEFLECTION FOR DIFFERENT HYPERELASTIC MODELS OF BIOMATERIAL.

\section{FREE VIBRATION OF A PLATE}

Free vibrations around different deformed configurations are investigated with the help of the harmonic balance method [18].

Fig. 3 displays the dimensionless backbone curves for free vibrations around the first eigenfrequency of the pre-loaded plate for the three hyperelastic laws. For corresponding static configuration the principal bending coordinate $w_{1,1}=70 \mathrm{~h}$. The comparison with the exact static solution shows that NeoHookean and Mooney-Rivlin local models are accurate for deflection up to $10 h$, but Ogden model is limited to deflections not larger $3 h$ only.

The evolution of the backbone curve with initial static deflection is shown in Fig. 4. We can see that nonlinearity weakens with the growth of initial deflection. We can see that the curves in Figs. 4 b)-4 d) are non-symmetric with respect to the horizontal axis due to the pre-load of the plate. For bended plates the amplitudes inward are greater than the amplitudes 
outward [14]. In Fig. 4 curves for Neo-Hookean material are shown; other material models exhibit similar behavior.

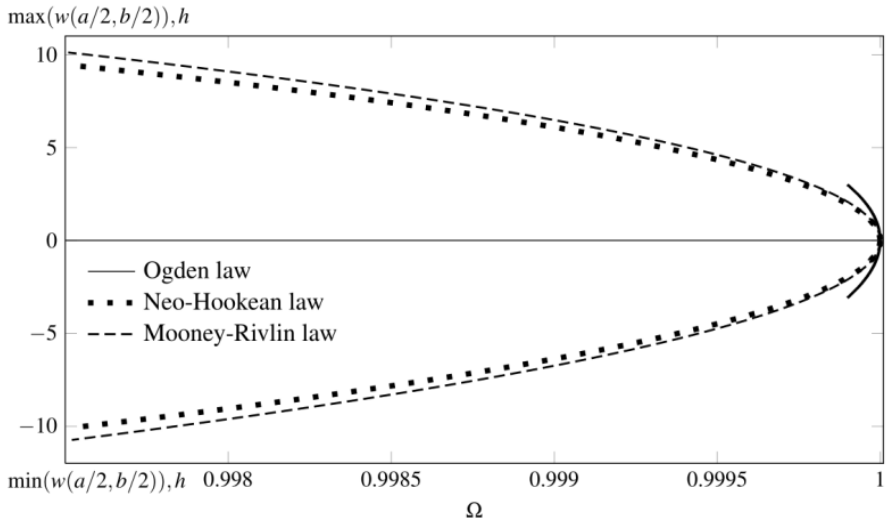

Figure 3. BACKBONE CURVES FOR FREE VIBRATIONS AROUND THE DEFORMED CONFIGURATION WITH $w_{1,1}=70 h$ FOR DIFFERENT HYPERELASTIC LAWS. NON-DIMENSIONAL FREQUENCIES, NORMALIZED WITH RESPECT TO THE FIRST NATURAL FREQUENCY OF THE DEFORMED PLATE, ARE SHOWN IN ABSCISSA.

The nonlinearity is of softening type and is very weak for all material models. The Neo-Hookean and Mooney-Rivlin backbone curve are very close and show a softer behavior than the Ogden curve.

\section{CONCLUSIONS}

Static deflection and free vibration of plate made of biological material are explored with the purposely created method. It is found that Mooney-Rivlin and Neo-Hookean materials exhibit similar behaviors. Corresponding constitutive laws properly capture the behavior of the actual material at moderate strains. The best approximation is provided by Ogden's model. The latter correctly reproduces the behavior at high strains, including the sharp increase in stiffness. However, this increase in stiffness limits the range of vibrations amplitudes which can be targeted.

It is also shown that the pre-loaded plate exhibits very weak dynamic nonlinearity, i.e. the frequencies of the oscillations around the deformed configuration are close to the associated eigenfrequencies.

The sensitivity of the backbone curves to the initial deflection is also discussed. It is shown that the higher the initial deflection, the higher the range of amplitudes at which the backbone curve displays softening behavior. Also, the frequency shift between low- and large-amplitude vibrations weakens with an increase of the initial deflection.

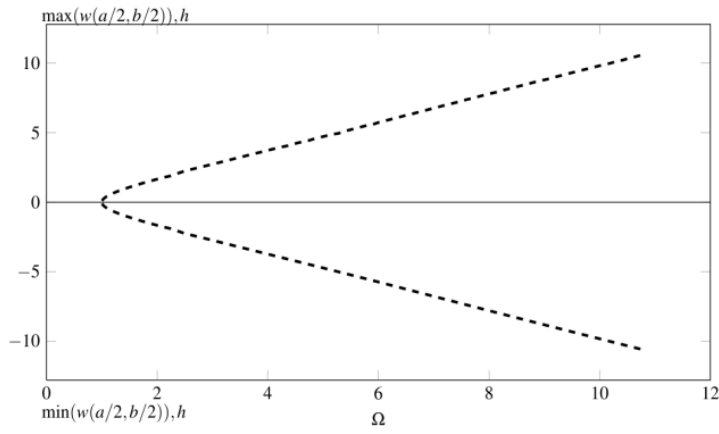

a)

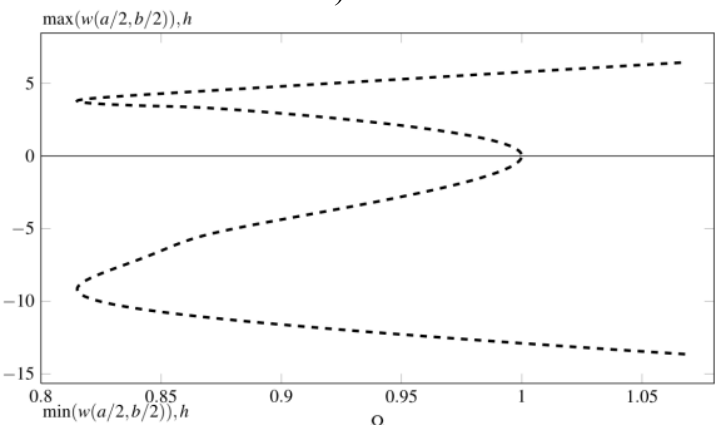

b)

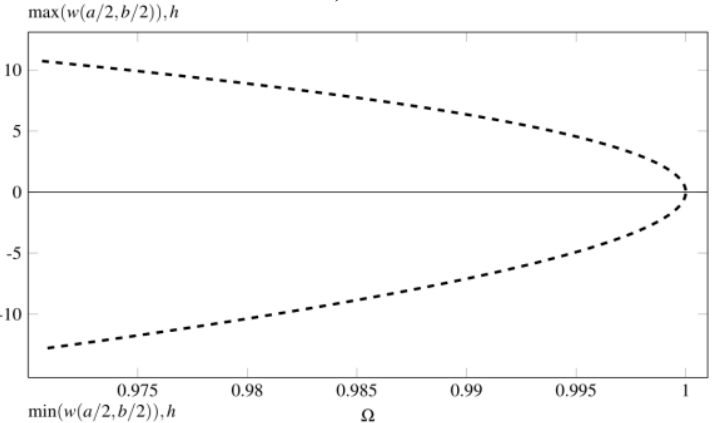

c)

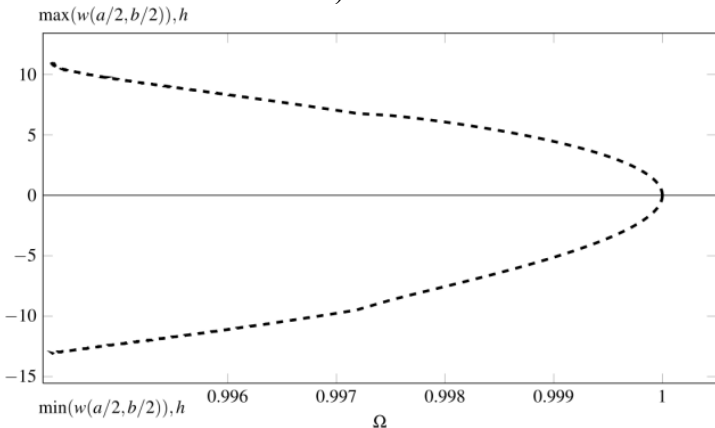

d)

Figure 4. BACKBONE CURVES FOR PLATE VIBRATIONS IN THE VICINITY OF DIFFERENT DEFORMED CONFIGURATIONS; NEO-HOOKEAN MODEL. a) $w_{1,1}=0$ (FLAT PLATE); b) $w_{1,1}=5 h$; c) $w_{1,1}=30 h ;$ d) $w_{1,1}=55 h$. 


\section{REFERENCES}

[1] Verron, E., Marckmann, G., Peseux, B., 2001. "Dynamic inflation of non-linear elastic and viscoelastic rubber like membranes". International Journal for Numerical Methods in Engineering, 50, pp. 1233-1251.

[2] Einstein, D.R., Reinhall, P., Nicosia, M., Cochran, R.P., Kunzelman, K., 2003. "Dynamic finite element implementation of nonlinear, anisotropic hyperelastic biological membranes". Computer Methods in Biomechanics and Biomedical Engineering, 6, pp. 33-44.

[3] Haslach, H.W., Humphrey, J.D., 2004."Dynamics of biological soft tissue and rubber: internally pressurized spherical membranes surrounded by a fluid." International Journal of Non-Linear Mechanics, 39(3), pp. 399-420.

[4] Yong, H., He, X., Zhou, Y., 2011. "Dynamics of a thickwalled dielectric elastomer spherical shell". International Journal of Engineering Science, 49(8), pp. 792-800.

[5] Breslavsky, I., Amabili, M., Legrand, M., 2014. "Physically and geometrically non-linear vibrations of thin rectangular plates". International Journal of Non-linear Mechanics, 58, pp. 30-40.

[6] Breslavsky, I., Amabili, M., Legrand, M., 2014. "Nonlinear vibrations of thin hyperelastic plates". Journal of Sound and Vibration, under review.

[7] Goncalves, P.B., Soares, R.M., Pamplona, D., 2009. "Nonlinear vibrations of a radially stretched circular hyperelastic membrane". Journal of Sound and Vibration, 327(1-2), pp. 231-248.

[8] Soares, R.M., Goncalves, P.B., 2012. "Nonlinear vibrations and instabilities of a stretched hyperelastic annular membrane". International Journal of Solids and Structures, 49(3-4), pp. 514-526.

[9] Soares, R.M., Goncalves, P.B., 2014. "Large-amplitude nonlinear vibrations of a Mooney-Rivlin rectangular membrane". Journal of Sound and Vibration, in press.

[10] Breslavsky, I.D., 2012. "Stress distribution over plates vibrating at large amplitudes". Journal of Sound and Vibration, 331(12), pp. 2901-2910.

[11] Holzapfel, G.A., 2006. "Determination of material models for arterial walls from uniaxial extension tests and histological structure". Journal of Theoretical Biology, 238, pp. 290-302.

[12] Ogden, R., 1997. Non-linear elastic deformations. Dover Publications, New York.

[13] Bower, A., 2010. Applied mechanics of solids. CRC Press. Taylor and Francis Group, Boca Raton.

[14] Amabili, M., 2008. Nonlinear vibrations and stability of shells and plates. Cambridge University Press, New York.

[15] Breslavsky, I.D., Avramov, K.V., 2013. "Effect of boundary condition nonlinearities on free large-amplitude vibrations of rectangular plates". Nonlinear Dynamics, 74, pp. 615627.

[16] Avramov, K.V., Breslavskii, I.D., 2013. "Vibrations of shallow shells rectangular in the horizontal projection with two freely supported opposite edges". Mechanics of Solids, 48(2), pp. 186-193.
[17] Breslavsky, I.D., Avramov, K.V., 2012. "Two modes nonresonant interaction for rectangular plate with geometrical nonlinearity". Nonlinear Dynamics, 69, pp. 285-294.

[18] Parker, T.S., Chua, L.O., 1989. Practical numerical algorithms for chaotic systems. Springer-Verlag, New York. 